(This preprint has not been peer reviewed.

It has been submitted to the journal JOULE for publication)

\title{
Is Net Zero Carbon 2050 Possible?
}

John Deutch, Department of Chemistry, MIT Cambridge Massachusetts

Is a goal of achieving Net Zero $\mathrm{CO}_{2}$ emissions by 2050 assure that the world will meet the 2015 Paris Agreement target of keeping global warming below $2^{\circ} \mathrm{C}$ ? If so, is it possible for the United States and the world to achieve the Net Zero 2050 goal? Unfortunately, the answer to both questions is "no."

Skepticism that the pace and magnitude of anthropogenic greenhouse gas, GHG, emission reductions are not sufficient to meet the $2^{\circ} \mathrm{C}$ target that has turned attention to the Net Zero emission goal, -- achieving a balance between reducing emissions into the atmosphere and removal of $\mathrm{CO}_{2}$ from the atmosphere through new "negative emissions" technologies.

Many are advocating adopting a strict goal of Net Zero $\mathrm{CO}_{2}$ emissions by the year 2050 to supercharge a decisive new effort to avoid pervasive climate. damage. Several jurisdictions have passed laws mandating the goal. ${ }^{1}$ Ten states including Massachusetts, New York and California have set a goal of a zero-carbon economy mid-century. ${ }^{2}$ The European Union has adopted a decarbonization strategy that it estimates will require an investment of $2.8 \%$ of GDP to achieve a net zero economy by $2050 .{ }^{3}$ Climate leaders are actively backing mid-century zero carbon initiatives. ${ }^{4}$ Leading private firms and organization are committing to net zero operations by $2050 .{ }^{5}$ It seems likely that if a Democratic team enters the White House in November it will propose legislation requiring the U.S. economy to be net zero by mid-century.

Are such goals realistic or are they aspirational? If the goals are aspirational, will they lead to greater effort or when they are shown to fail, will they contribute to even greater cynicism about government among investors and the public? How does the Net Zero by 2050 goal relate to the goal to maintain average temperature increase below $2{ }^{\circ} \mathrm{C}$ or preferably $1.5^{\circ} \mathrm{C}$ by 2100 ?
- Achieving NZ(2050) does not assure complying with a global warming temperature ceiling.

- The U.S. might achieve NZ(2050); the world almost certainly will not.

- For the U.S. to achieve NZ(2050) requires a massive transition of the economy, which is extremely unlikely. 
The average global temperature increase at any time is proportional to the logarithmic change in atmospheric $\mathrm{CO}_{2}$ concentration, $\mathrm{c}(\mathrm{t}): \delta \mathrm{T}(\mathrm{c})=\varepsilon \frac{\ln \left(\mathrm{c} / \mathrm{c}_{0}\right)}{\ln (2)}$. The equilibrium climate sensitivity, $\varepsilon$, is the temperature increase from a doubling of the concentration, If $\varepsilon=3, \varepsilon / \ln (2)=4.33$. The equilibrium climate sensitivity, $\varepsilon$, exhibits high statistical variation because of climate feedback mechanisms ${ }^{6}$ and lies between 1.5 and $4.5^{7}$

In 2020 the $\mathrm{CO}_{2}$ concentration will be about 400 ppmv, creating warming of about $1^{\circ} \mathrm{C}$ over preindustrial time. If Net Zero 2050 is achieved, the temperature increase in 2100 will be determined by the prevailing concentration c(2050) if there are no subsequent emissions during the intervening period 2050 to 2100 . Suppose the world is on a trajectory to remain below a $1.5^{\circ} \mathrm{C}, 2{ }^{\circ} \mathrm{C}, 3{ }^{\circ} \mathrm{C}$ ceiling at the end of the century. Adopting the equilibrium climate sensitivity $\varepsilon=3.0$, the concentration c(2100) must remain below 449 ppmv, 504 ppmv, and 635 ppmv respectively. The sign of $\Delta c .=[c(2100)-c(2050)]$ determines if the ceiling will be respected. If $\Delta \mathrm{c}>0$, the ceiling is respected. If $\Delta \mathrm{c}<0$, an amount of $\mathrm{CO}_{2}$ equal to $7.81 \mathrm{GtCO}_{2}|\Delta \mathrm{c}|$ will need to be removed from the atmosphere if the ceiling is to be respected. The quantity $\Delta \mathrm{c}$ is the carbon budget for the period between when Net Zero is achieved in 2050 and the concentration in 2100 corresponding to the adopted climate ceiling.

Achieving the Net Zero 2050 goal does not assure staying below a global warming temperature ceiling.

The statistical variation of the equilibrium climate sensitivity adds an additional complication. As an example, suppose the probability density for $\varepsilon$ is uniform over the region $1.5<\varepsilon<4.5$. Using the average $\langle\varepsilon\rangle=3.0$ leads to the concentration $449 \mathrm{ppmv}$ to remain under the $1.5^{\circ} \mathrm{C}$ temperature ceiling. Suppose the Net Zero 2050 program maintains this concentration to 2100 , there is a $50 \%$ chance that the warming will be less and a $50 \%$ chance that the warming will be worse: $\delta \mathrm{T}(2100)=1.5 \pm \sigma$, where $\sigma=0.87$ is the standard deviation. If the $2050 \mathrm{Net}$ Zero concentration is above 504 ppmv, it is certain that the $21001.5^{\circ} \mathrm{C}$ ceiling will be breached. If the 2050 Net Zero concentration is maintained below 432 ppmv, it is certain 1.5 ${ }^{0} \mathrm{C} 2100$ ceiling will be respected. The uniform probability density gives a symmetric result. However, if the statistical variation arises from feedback, the probability density for $\delta \mathrm{T}$ will exhibit a "fat tail," which is much more consequential. ${ }^{8}$ A detailed discussion of the REVISED 6/10/2020 
relationship of the probability of remaining below a specified temperature ceiling and variability in climate sensitivity is given by Lowe and Bernie. ${ }^{5}$

\section{A plausible pathway to Net Zero 2050 for the United States}

Global Net Zero requires eliminating all $\mathrm{CO}_{2}$ and eventually all other GHGs emissions, notably $\mathrm{CH}_{4}$ and $\mathrm{N}_{2} \mathrm{O}$, from every end-use sector. It means essentially restructuring the global energy system for all energy use: power, transportation, manufacturing and industrial operations, residential and commercial buildings, and land use for agriculture/husbandry/forestry. It is an enormous undertaking because of the sheer scale of the activities, representing a substantial fraction of global GDP, and the size of the investment to make the changes. There are extensive international trade flows that carry fuels and goods and services among all nations that operate with varying economic, political and social systems. Time also presents a challenge. At the scale requiring change, thirty years is a very short time. However, annual global GDP is about $\$ 90$ trillion, so allocating 5 to $10 \%$ to achieving Net Zero is in principle, if not in practice, possible. The U.S. GDP is about $\$ 20$ trillion annually, with $\$ 3.5$ trillion allocated to investment; the transformation cost could easily command up to $1 / 3$ of this amount. Hence the United States and other OECD countries arguably could bear the enormous Net Zero transition cost.

The United Nation's Framework Convention on Climate Change, UNFCC, the governance structure available for global climate policy and programs, has not been given the authority and responsibility for planning and implementing a global Net Zero program. Nor does the UNFCC have the financing or technical capability to address a problem of this scope. Its principal virtue has been and will continue to be providing a venue and a process - the annual Conference of the Parties, COPs - to engage over one hundred member countries who have different interests and priorities. It is hopeless to expect that the UNFCC's incremental approach, followed for almost half a century since the 1992 Kyoto Protocol, could effectively lead a global Net Zero initiative. Indeed, it is disappointment with progress resulting from the highly acclaimed 2015 Paris Agreement COP 21 that has led to an urgent call for the different Net Zero approach.

Moreover, it is unreasonable to expect that rapidly growing emerging economies in Africa and Asia that have social and economic goals that compete for available resources to adopt a Net Zero 2050 goal. Progress will require major resource transfer from developed economies, but 
they have not been honored their past commitments and there remains much debate about mechanisms for managing such assistance.

In sum, Net Zero in 2050 is possible for the US and OECD, but extremely unlikely for the many rapidly growing emerging economies. However, staying below $2^{\circ} \mathrm{C}$ until 2100 is possible for the world.

John Podesta and Todd Stern properly urge that the best way forward is for the United States, hopefully along with other OECD countries, to take the lead by committing to Net Zero in 2050. ${ }^{4}$ A more laudable goal, if it were feasible, would be to set the Net Zero 2050 goal for North America. If successful, it would be a powerful model for stitching together a climate policy coalition to bridge the interests of developed and developing nations.

\section{Achieving Net Zero in 2050 in the United States}

The path to Net Zero in the United States requires a transition to an essentially all electric economy. Such a transition begins with deep decarbonization of the electricity system by leveraging the tremendous penetration of renewable electricity generation - notably wind and solar. Additional measures are required to meet load demand when variable renewable electricity has penetration beyond about $70 \%$. The measures consist of over building renewable generation capacity, deploying storage systems, adding power transmission lines, and demand side management (paying consumers to shed load in times of extreme capacity shortage). The $\mathrm{CO}_{2}$ abatement costs are reasonable for substantial reductions but increase very sharply beyond $90 \%$ reduction, reaching perhaps $\$ 5,000$ per $\mathrm{MW}_{\mathrm{e}}-\mathrm{hr}$ at the intercept with zero emissions

When deep carbon free electricity is attained and scalable, the next step is to electrify the transportation sector to the extent possible. Together these two steps would reduce U.S. GHG emissions by at most $80 \%$. Displacing the additional $20 \%$ of $\mathrm{CO}_{2}$ emissions that come from agriculture and some industrial activities - buildings, construction, and manufacturing with electricity will be more challenging. ${ }^{9}$ At higher levels of emissions reductions, net negative emission technologies will be required to reach Net Zero, preserving fossil fuels for certain uses, e.g., aircraft fuel, chemical production, agriculture and livestock.

Innovation has an important role in the Net Zero initiative. ${ }^{10}$ Progress must continue on energy efficiency and clean energy technologies. Negative emission technologies such as 
afforestation/reforestation, bioenergy, Bioenergy and direct air capture of $\mathrm{CO}_{2} \mathrm{DAC}$, are at early stages of technology readiness but important atmospheric $\mathrm{CO}_{2}$ removal. An aggressive and well financed research, development and demonstration effort will be required to meet the 2050 target date. So far it has not proven possible to deploy two large scale zero carbon energy technologies deployment despite years of effort: commercial nuclear power and carbon capture utilization and storage. The bioenergy and DAC negative emission technologies require available CCUS options. Practical and economic CCUS options would also open opportunities, albeit perhaps expensive for clean coal and natural gas electricity generation. It is worth underscoring that successful innovation will require the integration of technical advance with economics, regulatory compliance, and good business practice.

\section{The U.S. mobilization gap}

Net Zero initiative presently consists of high-level goals, passionately advocated by committed climate policy individuals, which stress the need for leadership, a whole of government approach, and mobilization of public and private entities to meet the global existential climate change threat.

However, there is no concrete plan for achieving Net Zero by 2050 that lays out a schedule for advancing the needed new negative emission technologies, designing the extensive regulatory and market changes required for an all-electric economy, rebalancing federal and state authorities and responsibilities, dealing with trade issues between Net Zero U.S. and GHG emitting countries.

It is unlikely that the transition to an all-electric economy can be accomplished by incremental steps. Thirty years is not a long time to bring about changes of this scale. Fundamental change is necessary in executive branch agency organization, in the private sector where investment decisions between competing firms are based on price signals, as well as congressional oversight. The extent and pace of change is comparable to what is required in wartime based on public understanding and support. If these elements are not in place, a Net Zero 2050 initiative will not succeed in the United States.

\footnotetext{
${ }^{1}$ In law: Denmark, France, New Zeeland, Norway (2030), Sweden (2045), U.K.,

${ }^{2}$ Center for American Progress. "Fact Sheet: A 100 Percent Clean Future"

${ }^{3}$ https://ec.europa.eu/clima/policies/strategies/2050_en
} 
${ }^{4}$ J. Podesta and T. Stern, A Foreign Policy for the Climate, Foreign Affairs, May/June 2020; F. Krup, N. Keohane, and E. Pooley, Less than Zero; Foreign Affairs, March/April 2019, Klaus Schwab, World Economic Forum, January 14, 2020; Christina Figueres, former Executive Secretary, UNFCCC.

${ }^{5}$ Among these are, Shell, BP, Barclay's Bank, and the Harvard University.

${ }^{6}$ Interestingly, Fires are expected to have an effect but it is not known if the effect is cooling or warming

7 Collins, M. et al. Long-term climate change: projections, commitments and irreversibility. In Climate Change 2013: The Physical Science Basis. WG I to the Fifth Assessment Report of the IPCC, Ch. 12. $\delta \mathrm{T}(\mathrm{t})=\varepsilon \ln \left(\mathrm{c}(\mathrm{t}) / \mathrm{C}_{\text {pre }}\right.$ ${ }^{8}$ G. H. Roe \& M. Baker, Why is climate sensitivity so unpredictable? SCIENCE 318, 630 (2007).

${ }^{9}$ EPA Sources of U.S. GHG Emissions 2018 https://www.epa.gov/ghgemissions/sources-greenhouse-gas-emissions

${ }_{10}$ National Research Council, Negative Emissions Technologies and Reliable Sequestration: A Research Agenda, 2018.

https://www.nap.edu/resource/25259/Negative\%20Emissions\%20Technologies.pdf. 